\title{
Hypnotic Sex Change: Creating and Challenging a Delusion in the Laboratory
}

\author{
Jason Noble \\ Macquarie University
}

\author{
Kevin M. McConkey \\ University of New South Wales
}

\begin{abstract}
The authors suggested a change of sex to virtuoso, high-hypnotizable, and low-hypnotizable simulating participants in an application of the real-simulating paradigm of hypnosis. The experiences of sex change that participants reported during hypnosis were challenged through procedures of contradiction and confrontation. Behavioral and self-report data indicated that virtuosos experienced a transient delusion about their sex that was compelling and resistant to challenge. Implications are discussed for investigations of delusion through the use of hypnosis in the laboratory and for understanding delusion in the clinical setting.
\end{abstract}

A delusion occurs when a person holds a belief that others do not share and consider incredible given the balance of evidence for and against the belief. This belief is typically one that involves personal reference, preoccupies the person, and interferes with the person's functioning; moreover, the person holds the belief with conviction, does not resist the belief, and is unresponsive to evidence contrary to the belief (Oltmanns, 1988 ). Delusions have been explained by unconscious motivation (Freud, 1911/1958), breakdowns in logical reasoning (Hemsley \& Garety, 1986; Winters \& Neale, 1983), attempts to explain anomalous experiences (Maher, 1988; Reed, 1988), and self-deception (Sarbin, 1981, 1988). Limited empirical advances have been made in understanding delusions, due to their fundamentally private nature, the heterogeneity of psychopathological delusions, and the problems of clinical research. One way of achieving some advance, however, is by bringing delusions into the laboratory through hypnosis.

Delusion and hypnosis correspond in a number of ways (Kihlstrom \& Hoyt, 1988). Both involve personal reference, experiences that are not shared by others, and conflict with external information. Theoretical comments from various perspectives about hypnosis underscore its relevance to understanding delusion. Sutcliffe (1961), for instance, argued that "the main feature of [hypnosis] is the hypnotized subject's emotional conviction that the world is as suggested by the hypnotist" (p. 200). Orne (1959) emphasized that "an important attribute of hypnosis is a potentiality for the [subject] to experience as subjectively real suggested alterations in his environment that do not conform with reality"' (p. 297). Sarbin (1981)

Jason Noble, Department of Psychology, Macquarie University, Sydney, Australia; Kevin M. McConkey, School of Psychology, University of New South Wales, Sydney, Australia.

This research was supported in part by a grant from the Australian Research Council. We are grateful to Amanda Barnier, Heather Wilton, Sandra Hejtmanek, and Fiona Maccallum for assistance in the conduct of the research.

Correspondence concerning this article should be addressed to Kevin M. McConkey, School of Psychology, University of New South Wales, Sydney NSW 2052, Australia. highlighted that hypnosis involves "convincingly expressing belief in a counterfactual proposition in the presence of contradictory evidence" (p. 222). Spanos and Barber (1974) indicated that hypnotized people have "a tendency to carry out and also to elaborate imaginings consistent with the suggestions ... [and] to simultaneously ignore or reinterpret information that contradicts the imaginings" (p. 503). Because hypnosis allows the creation of transient delusions that can be controlled and manipulated in healthy individuals (Kihlstrom \& Hoyt, 1988; McConkey, 1991; see also Zimbardo, Andersen, \& Kabat, 1981 ), it is a potentially valuable way of investigating delusions.

Accordingly, we used a hypnotic suggestion for changing a person's sex as the basis of our experiment. In developing and using this suggestion, we were conscious of the confusion that surrounds sex and gender in the scientific and public use of these terms (see Deux, 1993; Gentile, 1993; Unger \& Crawford, 1993). In both formal and informal language, these terms are sometimes used interchangeably and sometimes with specific meaning (cf. race and ethnicity). For our purposes, we chose to refer to sex change rather than gender change, because that was consistent with Sutcliffe (1961). In particular, a suggestion for sex change was consistent with his argument that hypnotically induced delusion should involve a suggestion for a change in "the person or his ego" (p. 197). Sutcliffe (1961) gave positive (i.e., "you are a man/woman") and negative (i.e., "you are not a man /woman") versions of a sex change suggestion to hypnotized and unhypnotized people. He reported that more hypnotized than unhypnotized people responded to the suggestion, and that more hypnotized people responded to the negative than the positive version of the suggestion; he concluded that "the qualitative data support the view that in a number of cases hypnotized subjects were deluded about their sex" (p. 199). On the basis of Sutcliffe (1961), we developed a suggestion for sex change and used positive and negative versions.

A characteristic of hypnosis is the belief that people develop in the genuineness of the suggested effects (McConkey, 1991; Sutcliffe, 1961). McConkey (1991) argued that hypnotized people react to challenges to these suggested effects in ways that provide important information about the nature of their experiences. Similarly, but with respect to delusion, Hemsley and 
Garety (1986) argued that confronting deluded patients with evidence that refutes their clinical delusion sheds light on the nature and maintenance of those delusions. Therefore, we considered that one way of investigating created delusions would be by using procedures that challenge those delusions.

Accordingly, we devised two procedures to challenge the hypnotically created delusion of sex change. Contradiction involved the hypnotist asking participants what they would say if a hypothetical "doctor" entered the room, examined them, and said there was no reason for them to say that they were the sex opposite to their actual sex. The intent was to provide a contradiction of their experience by a hypothetical authority figure as a way of exploring whether this interfered with the hypnotic delusion. Confrontation involved the hypnotist asking participants to open their eyes and look at an image of themselves on a video monitor directly in front of them. The intent was to provide a confrontation of their experience through conflicting visual material as a way of exploring whether this interfered with their behavioral response or subjective conviction.

We used the real-simulating paradigm of hypnosis (Orne, 1959). This paradigm compares the performance of real, hypnotized people with that of simulating, unhypnotized people who are motivated to respond to the demands of the hypnotic setting. We used two types of real, hypnotized participants: virtuosos and high-hypnotizable people. Virtuosos are those who responded exceptionally on standard tests of hypnotizability and thus have the capacity to experience a wide range of hypnotic items (Register \& Kihlstrom, 1986). Given the complexity of the hypnotic item and the challenge procedures in the present experiment, both virtuoso and high-hypnotizable participants served as reals. Low-hypnotizable participants served as simulators. The simulating condition is a quasicontrol that provides an index of what constitutes an appropriate response, given the total nexus of demand cues in the experimental setting. If the responses of reals and simulators are similar, then the appropriate inference is that sufficient information exists in the setting for unhypnotized participants to determine the expected response. If the responses of reals and simulators are different, then reals can be said to be responding in a way that reflects features of their involvement that are not based on the demand characteristics of the setting as indexed by the responses of simulators.

\section{Method \\ Participants}

We tested 18 virtuoso participants ( 6 men and 12 women, mean age $=19.78$ years, $S D=5.66) ; 18$ high-hypnotizable participants ( 5 men and 13 women, mean age $=22.94$ years, $S D=7.67$ ); and 36 low-hypnotizable, simulating participants ( 14 men and 22 women, mean age $=25.36$ years, $S D=11.49$ ). Participants were students at Macquarie University (in Sydney, Australia) and voluntarily participated in exchange for research credit. The students had been preselected on the basis of their scores on the 12-item Harvard Group Scale of Hypnotic Susceptibility, Form A (HGSHS:A; Shor \& Orne, 1962), and on a 10item version of the Stanford Hypnotic Susceptibility Scale, Form C (SHSS:C; Weitzenhoffer \& Hilgard, 1962). Virtuosos scored 10-12 on the HGSHS:A $(M=10.78, S D=0.73)$ and a perfect 10 on the SHSS: C; high-hypnotizable students scored $10-11$ on the HGSHS:A $(M=$ $10.39, S D=0.50)$ and $8-9$ on the SHSS:C $(M=8.67, S D=0.49)$; and low-hypnotizable, simulating students scored $0-3$ on the HGSHS:A $(M=2.22, S D=0.90)$ and $0-3$ on the SHSS:C $(M=1.53, S D=1.00)$.

\section{Materials and Apparatus}

A videocamera connected to a videocassette recorder was used to record the experimental testing. The camera was mounted on a tripod approximately $2 \mathrm{~m}$ in front of the student, and the camera was focussed on the student at all times. A video monitor was placed at the student's eye level on a table approximately $2 \mathrm{~m}$ in front of him/her. This allowed the student to view the image on the monitor when requested to do so.

\section{Procedure}

The experiment involved three phases: preexperimental instructions, experimental testing, and postexperimental inquiry. There were two experimenters: one gave the preexperimental instructions and conducted the postexperimental inquiry; the other was the hypnotist, who was blind to the real or simulating status of the participants and who conducted the experimental testing.

\section{Preexperimental Instructions}

The first experimenter gave the students a brief description of the experiment and asked them to sign an informed consent form. The experimenter then treated them according to their status as real (virtuoso and high hypnotizable) or simulating (low hypnotizable) participants. Reals were told that their performance in the previous hypnosis sessions had been excellent and that they had exactly the sort of abilities that could help in the research. They were told they would be introduced to a second experimenter (i.e., the hypnotist ) who would conduct a hypnosis session with them, and the first experimenter would meet them after the hypnosis session to discuss their experiences.

Simulators were reminded that they had tried to enter hypnosis in previous sessions and had found it difficult to do so. They were told they would be introduced to a second experimenter, and their task would be to pretend they were excellent hypnotic candidates and able to enter deep hypnosis. They were told to make the hypnotist think they were deeply hypnotized and to do this by using whatever they knew about hypnosis, whatever cues they got from the hypnotist, and whatever they learned from the situation to work out how a deeply hypnotized person would behave. They were instructed not to tell the hypnotist that they were faking, and they were told that the hypnotist would stop the experiment if she caught on to them. The first experimenter told simulators he would meet them after the hypnosis session to discuss their experiences with them and stressed they should not make any comments about their faking until then. The first experimenter then took students to the hypnosis setting and introduced them to the second experimenter.

\section{Experimental Testing}

The hypnotist gave the students a brief description of the session without mentioning any particular hypnotic suggestions and rated the subjects' status as either real or simulating. She then started the videorecording and administered the standard hypnotic induction procedure of the SHSS:C. Following this induction procedure, the hypnotist gave suggestions for arm lowering, heat hallucination, arm levitation, sex change, and a posthypnotic suggestion.

Suggestion. Following Sutcliffe (1961), we used two versions of the sex change suggestion; half the participants received one version, and half the other. In the "positive" version it was suggested that the student was the opposite sex; in the "negative" version it was suggested that the student was not his/her actual sex. In essence, the suggestion conveyed: "In a moment you will [be]/[no longer be] a man/woman, you will 
[be]/[ no longer be] male/female in [every]/[any] way." The suggestion continued for $3 \mathrm{~min}$. Approximately $30 \mathrm{~s}$ after the suggestion, the experimenter asked "Tell me about yourself?" and "What is your name?".

Contradiction. The contradiction consisted of the following addressed to the students:

As you sit there experiencing yourself, I want you to think about something. If a doctor came into the room now and examined you and said that he/she [same sex as subject] could find no reason for you [not] to be male/female, then what would you say to the doctor?

Confrontation. The video presentation was used for the confrontation as follows:

In a moment, as you sit there relaxed and deeply hypnotized, l'll ask you to open your eyes. When I ask you to open your eyes I'll get you to look at the television screen that's directly in front of you ... All right ... just open your eyes and look at the monitor. Tell me now, what are you experiencing as you look at yourself on the screen?

After allowing the students to comment on the video image, the hypnotist cancelled the sex change suggestion and asked them to close their eyes and relax. A posthypnotic suggestion and the SHSS:C deinduction procedure were then administered.

The hypnotist then conducted a brief experimental inquiry. Students were asked to rate the reality of their experience of sex change as follows: "When I told you that you were [becoming male/female]/[ no longer male/female], how real did it seem to you that that was occurring, where 0 means not at all real and 6 means extremely real?" The hypnotist also recorded any comments made about their sex change suggestion. Finally, the hypnotist rated the status of the participant as real or simulating, and thanked and escorted him/her to the first experimenter.

\section{Postexperimental Inquiry}

When the participants returned, the first experimenter asked simulators to comment on how well they thought they had faked hypnosis and whether they had experienced any suggested effects. He asked all of them to describe their reactions to the sex change suggestion. Specifically, he asked: "Can you tell me what you thought about when the hypnotist told you that you were [becoming male/female]/[no longer male/female]?"; "What about the doctor?"; "What about the video?"; and "How real did it seem to you that your sex was changing, where 0 means not at all real and 6 means extremely real?". Finally, he asked them if they had any questions or comments, thanked them for their participation, and ended the session.

\section{Analysis of Videorecorded Material}

The videorecording of the experimental testing was examined by the hypnotist, who was still blind to the status of the students, and by an independent rater, who also was blind to their real or simulating status. They both classified students' responses to the contradiction and confrontation procedures in terms of whether the students maintained their responses to the sex change suggestion. Maintaining the effect was indexed by their comments indicating that they were experiencing the suggested sex change. For contradiction, comments that indicated maintenance of the effect included questioning the doctor's abilities, making disparaging remarks about the doctor, and pointing to physical signs or feelings that confirmed the suggestion. For confrontation, comments that indicated maintenance included noting features of the video image that were congruent with the suggestion, seeing the image as someone else, and asserting the experience by pointing to physical features or emotional feelings consistent with the suggestion.

\section{Results}

The hypnotist scored participants as responding positively to the sex change suggestion if they did not deny the suggested effect when asked to comment at the end of the suggestion. ${ }^{1}$ The "positive" and "negative" versions of the suggestion did not influence the findings on any dependent variables, so the two versions are considered together. Eighteen ( $100 \%$ ) virtuosos, 16 (89\%) highs, and $36(100 \%)$ simulators responded positively to the sex change suggestion; chi-square analysis indicated no significant difference. Our subsequent analyses focused on those 70 students who responded positively to the sex change suggestion.

During the experimental inquiry, the students rated on a 7-point scale how real it seemed that they had become male/ female. A one-way analysis of variance of these ratings for the virtuosos $(M=4.78, S D=1.35)$, highs $(M=2.93, S D=2.02)$, and simulators $(M=3.56, S D=1.69)$ indicated a significant effect, $F(2,64)=5.31, p<.01$; post hoc Scheffe comparisons indicated that virtuosos rated their experience of sex change as more real than did either highs or simulators $(p<.05)$.

When asked their name after the suggestion, $11(61 \%)$ virtuosos, $3(19 \%)$ highs, and $13(36 \%)$ simulators reported a name consistent with the suggested sex change; chi-square analysis indicated a significant difference, $\chi^{2}(2, N=70)=6.61, p<.05$. Whereas most virtuosos changed their name to one consistent with the suggestion, most highs and simulators did not. A twoway analysis of variance (Subject Grouping $\times$ Name Response) of the experimental inquiry reality ratings of virtuosos, highs, and simulators who did and did not change their name indicated a significant main effect for name response, $F(1,61)=$ $9.93, p<.01$. Those who changed their name $(M=4.73, S D=$ 1.12) rated their experience of sex change as more real than those who did not change their name $(M=3.12, S D=1.87)$.

\section{Contradiction and Confrontation}

Responses to the challenge procedures were categorized by the hypnotist and an independent rater in terms of whether students did or did not maintain their positive response to the suggestion; the interrater agreement was $96 \%$.

For contradiction, $15(83 \%)$ virtuosos, 7 (44\%) highs, and $22(61 \%)$ simulators maintained their positive response to the suggestion; chi-square analysis indicated no significant difference. A two-way analysis of variance (Subject Grouping $\times$ Maintenance Response) of the experimental inquiry reality ratings of the virtuosos, highs, and simulators who did and did not maintain their positive response indicated a significant main effect for response, $F(1,61)=22.14, p<.001$. When faced

\footnotetext{
${ }^{1}$ In terms of the real-simulating paradigm, the hypnotist correctly identified $45(63 \%)$ students, specifically, 25 reals $(69 \%)$ and 20 simulators (56\%). Postexperimentally, all simulators thought they had faked hypnosis successfully, and none indicated experiencing effects suggested by the hypnotist.
} 
with the hypothetical doctor, students who maintained their response $(M=4.51, S D=1.20)$ rated their experience of sex change as more real than those who did not maintain their response $(M=2.38, S D=1.88)$.

For confrontation, $11(73 \%)$ virtuosos, $0(0 \%)$ highs, and 9 (41\%) simulators continued to maintain their positive response to the suggestion; chi-square analysis indicated a significant difference, $\chi^{2}(2, N=44)=10.72, p<.01$. Whereas most virtuosos maintained their positive response to the suggestion in the face of the video presentation, most highs and simulators did not. A two-way analysis of variance (Subject Grouping $\times$ Maintenance Response) of the experimental inquiry reality ratings of virtuosos and simulators who did and did not maintain their positive response (no highs maintained their positive response) indicated no significant effects.

\section{Postexperimental Inquiry Information}

During the postexperimental inquiry, participants rated on a 7-point scale how real it had seemed that their sex was changing in response to the suggestion; at this stage simulators were no longer faking. We conducted separate $t$-test comparisons to determine whether those who maintained a positive response during the confrontation procedure gave similar ratings of reality during the experimental inquiry (i.e., to the hypnotist) and in the postexperimental inquiry (i.e., to the first experimenter). These comparisons indicated that the reality ratings of virtuosos (experimental $M=4.78, S D=1.35$; postexperimental $M=$ $4.53, S D=1.37$ ) and highs (experimental $M=2.93, S D=$ 2.02; postexperimental $M=2.39, S D=2.06$ ) were similar across the two inquiries. For simulators, of course, the postexperimental inquiry ratings ( $M=0.22, S D=0.44)$ were signifcantly lower, $t(8)=11.59, p<.001$, than the experimental inquiry ratings $(M=3.56, S D=1.69)$.

During the postexperimental inquiry, virtuosos typically described their experience of sex change as an involuntary one. For instance, "It was really easy to go into that state," and "I could just feel it, I was just concentrating." Ten ( $56 \%$ ) virtuosos and $4(25 \%)$ highs described their experience of sex change as involuntary. Others, however, reported the use of specific, conscious strategies to experience the effect. Seven (39\%) virtuosos and $10(63 \%)$ highs made comments such as: "I just thought how a woman has her fingers, and that made me feel more feminine," and "I was trying to imagine the physical aspects, like short hair and hairy legs." One virtuoso (6\%) and 2 highs ( $13 \%$ ) reported an experience that involved neither involuntariness nor conscious strategies. Virtuosos generally reported that the sex change was compelling. For example, "It was so real it was disgusting," "I could actually feel myself changing," and "I felt really tall, I grew remarkably quickly." Twelve (67\%) virtuosos and $3(19 \%)$ highs described their experience in this way; $\chi^{2}(1$, $N=34)=7.89, p<.005$. Five $(28 \%)$ virtuosos and $12(75 \%)$ highs indicated a partial response to the suggested effect. For instance, "Some of it felt real, and other parts I felt, I can't be a boy," and "Well, I knew that I was female, but I suppose because I was under, I was male." It was not clear from the comments of $1(6 \%)$ virtuoso and $1(6 \%)$ high whether their experiences were compelling or partial. Most $(21 ; 58 \%)$ simulators reported confusion as to how they should act during the sex change sugges- tion. Typical comments were "I thought, "Oh no, how am I going to do this?"," and "I had to think about it for a while." Six (17\%) simulators mentioned trying not to laugh on first hearing the suggestion.

In terms of contradiction, most virtuosos commented that they thought the doctor was simply wrong in asserting their (actual) sex. For instance, "I said the doctor would be nuts," "That was unbelievable, because I was definite I was male," and "I said that he could clearly see that I had breasts and that I didn't have a penis, so I thought he must be a quack not to notice." Ten (56\%) virtuosos and only 2 (13\%) highs said that the doctor was wrong. Others said the doctor was not really in a position to decide on their sex. For instance, "I just felt he couldn't see things on the same level I was seeing them," and "I said that it wasn't physical attributes that made me a male, it was all mental." Five (28\%) virtuosos and $4(25 \%)$ highs gave this type of response. In contrast, $3(17 \%)$ virtuosos and 8 (50\%) highs agreed with the doctor, at least in part. For instance, "I wasn't sure, deep down I knew I was female but I wasn't, so I said that's wrong." The comments of $2(13 \%)$ highs concerning the doctor were ambiguous.

In terms of confrontation, virtuosos often said that the image on the screen was not them. For instance, "That wasn't me, that was someone else there," and "There was a girl sitting there watching the telly. She didn't have anything to do with what was actually going on." Seven (39\%) virtuosos and none of the highs described this experience. Others recalled being confused because what they were feeling conflicted with what they were seeing. Six (33\%) virtuosos and $2(13 \%)$ highs made comments such as "It was a male in the picture but it should have been female, it was definitely wrong," and "It felt all disjointed because I felt like I shouldn't have looked like that, or felt like that." Two (11\%) virtuosos and 2 (13\%) highs described features of the video image that partially confirmed their experience of sex change. For instance, "It emphasized the way I felt with my shoulders." Five (28\%) virtuosos and $16(100 \%)$ highs said that looking at the video image lessened their feelings of their sex having changed. For instance, "It just looked like me on the telly," "That wasn't too real. I can just remember seeing myself," and "I could still see me."

\section{Discussion}

We examined the responses of virtuoso, high-hypnotizable and low-hypnotizable, simulating students to the hypnotic suggestion of sex change and to the challenge procedures of contradiction and confrontation. Virtuosos rated the sex change experience as more real than did either highs or simulators, and they were more likely to change their name to one consistent with the suggested sex. Moreover, virtuosos were more likely than highs and simulators to maintain their response in the face of the confrontation (video presentation) procedure. Postexperimentally, virtuosos indicated they found the sex change experience to be compelling, whereas highs indicated they found it to be somewhat variable and incomplete; simulators reported that they faked their responses and said they found the challenge procedures to be confusing. The difference between the behavior of virtuosos and simulators implies that the virtuosos' actions and self-reports cannot be accounted for solely by the de- 
mand characteristics of the setting. Virtuosos reported a vivid and compelling experience of hypnotic sex change, and it seems likely that an internally generated experience led them to respond differently to simulators. Our findings are consistent with Sutcliffe (1961) that some hypnotized people will experience hypnotic sex change in a delusory fashion. These findings are consistent with the various theoretical views of Sutcliffe (1961), Orne (1959), Sarbin (1981), and Spanos and Barber (1974), and this fact underscores the need for both cognitive and social approaches to be integrated in explaining hypnotic phenomena (McConkey, 1991).

Unlike Sutcliffe (1961), we found that participants responded similarly to the positive and negative versions of the suggestion, but that difference may be accounted for by the more than 30-year time span between Sutcliffe and the present experiment. Much has happened in the nature and perceptions of sex and gender in those 30 years, and people's views of their biological sex and their socially defined sex roles are of undoubted relevance to work such as the present experiment (for a discussion of sex and gender, see Deux, 1993; Gentile, 1993; Unger \& Crawford, 1993). Most simply, a temporary experience of changed sex (or gender) is perhaps more socially acceptable now than when Sutcliffe's research was conducted.

More importantly, a finding across Sutcliffe (1961) and our experiment was that some people expressed conviction in their sex change when they were asked or challenged about their experience. That is, for most virtuosos and many highs, the hypnotic delusion was characterized by strong subjective conviction. The comments of virtuosos and highs indicated that their experience of sex change showed characteristics of delusion. Namely, it reflected a belief others didn't share and would find incredible, it involved personal reference, it was held with conviction, and it was unresponsive to contrary evidence ( see Oltmanns, 1988). Thus, among exceptional people hypnotic delusions analogous to clinical delusions can be established and can be seen to display resistance to challenge. This is consistent conceptually with Zimbardo et al's ( 1981) finding that people who were given hypnotic deafness suggestions became more paranoid as indicated on various assessments, and that the hypnotically induced experience was similar to a clinical experience.

The use of challenge procedures provided useful information about peoples' delusional experiences. Many reinterpreted the conflicting information in ways that confirmed their experience. The most striking example of this was the way in which some virtuosos described the video image as being "not me"; they worked to deal with information that was inconsistent with their experience, and this management of conflicting information may be an important aspect of delusion (McConkey, 1991). For instance, clinically it may be that, rather than delusional patients simply ignoring contrary evidence, perhaps the process is one of reinterpreting and absorbing information in a way that makes their private experience coherent and meaningful. Understanding the interpretation and reinterpretation of experience that is inconsistent with objective reality can be approached from various theoretical points (e.g., Lockard \& Paulhus, 1988; Oltmanns \& Maher, 1988; Reed, 1988; Sheehan \& McConkey, 1982), and the question of how people give meaning to their experience is necessarily one that involves an interactionist perspective.
Some students maintained their belief in the face of both contradiction and confrontation, but some did not. This suggests that clinical delusions may not be unassailable, and there is clinical evidence consistent with this view. For instance, Hemsley and Garety (1986) argued that the systematic presentation of contrary evidence is one way of working to reduce clinical delusions, and Johnson, Ross, and Mastria (1977) described a case of successful treatment of a delusion by eventually convincing a patient that his delusional explanation of an event was not correct. In this respect, future research could explore the impact of challenge on hypnotically deluded people. Whether false beliefs are slowly reduced by additive instances of contrary information or breached only by overwhelming contrary evidence is one question that needs to be addressed. In understanding the psychology of delusions, hypnosis provides a technique for answering this and other questions in the laboratory.

\section{References}

Deux, K. (1993). Commentary: Sorry, wrong number-A reply to Gentile's call. Psychological Science, 4, 125-126.

Freud, S. (1958). Psychoanalytic notes on an autobiographical account of a case of paranoia (dementia paranoides). In J. Strachey (Ed. and Trans.), Standard edition of the complete works of Sigmund Freud (Vol. 12, pp. 9-82). London: Hogarth Press. (Original work published 1911)

Gentile, D. A. (1993). Just what are sex and gender, anyway? A call for a new terminological standard. Psychological Science, 4, 120-122.

Hemsley, D. R., \& Garety, P. A. (1986). The formation and maintenance of delusions: A Bayesian analysis. British Journal of Psychiatry. $149,51-56$

Johnson, W., Ross, J., \& Mastria, M. (1977). Delusional behavior: An attributional analysis of development and modification. Journal of Abnormal Psychology, 86, 421-426.

Kihlstrom, J. F., \& Hoyt, I. P. (1988). Hypnosis and the psychology of delusions. In T. F. Oltmanns \& B. A. Maher(Eds.), Delusional beliefs (pp. 66-109). New York: Wiley.

Lockard, J. S., \& Paulhus, D. L. (Eds.). (1988). Self-deception: An adaptive mechanism? Englewood Cliffs, NJ: Prentice Hall.

Maher, B. A. (1988). Anomalous experience and delusional thinking: The logic of explanations. In T. F. Oltmanns \& B. A. Maher (Eds.), Delusional beliefs ( pp. 15-33). New York: Wiley.

McConkey, K. M, (1991). The construction and resolution of experience and behavior in hypnosis. In S. J. Lynn \& J. W. Rhue (Eds.), Theories of hypnosis: Current models and perspectives (pp. 542563). New York: Guilford Press.

Oltmanns, T. F. (1988). Approaches to the definition and study of delusions. In T. F. Oltmanns \& B. A. Maher (Eds.), Delusional beliefs (pp. 3-11). New York: Wiley.

Oltmanns, T. F., \& Maher, B. A. (Eds.). (1988). Delusional beliefs. New York: Wiley.

Orne, M. T. (1959). The nature of hypnosis: Artifact and essence. Journal of Abnormal and Social Psychology, 58, 277-299.

Reed, G. (1988). The psychology of anomalous experience: A cognitive approach (Rev. ed.). Buffalo, NY: Prometheus.

Register, P. A., \& Kihlstrom, J. F. (1986). Finding the hypnotic virtuoso. International Journal of Clinical and Experimental Hypnosis, 34, 84-97.

Sarbin, T. R. (1981). On self-deception. Annals of the New York Academy of Sciences, 364, 220-235.

Sarbin, T. R. (1988). Self-deception in the claims of hypnosis subjects. In J. S. Lockard \& D. L. Paulhus (Eds.), Self-deception: An adaptive mechanism? (pp. 99-112). Englewood Cliffs, NJ: Prentice Hall. 
Sheehan, P. W., \& McConkey, K. M. (1982). Hypnosis and experience: The exploration of phenomena and process. Hillsdale, $\mathrm{NJ}$ : Erlbaum.

Shor, R. E., \& Orne, E. C. (1962). Harvard Group Scale of Hypnotic Susceptibility, Form A. Palo Alto, CA: Consulting Psychologists Press.

Spanos, N. P., \& Barber, T. X. (1974). Toward a convergence in hypnosis research. American Psychologist, 29, 500-511.

Sutcliffe, J. P. (1961). "Credulous" and "skeptical" views of hypnotic phenomena: Experiments in esthesia, hallucination and delusion. Journal of Abnormal and Social Psychology, 62, 189-200.

Unger, R. K., \& Crawford, M. (1993). Commentary: Sex and genderThe troubled relationships between terms and concepts. Psychological Science, 4, 122-124.
Weitzenhoffer, A. M., \& Hilgard, E. R. (1962). Stanford Hypnotic Susceptibility Scale, Form C. Palo Alto, CA: Consulting Psychologists Press.

Winters, K. C. \& Neale, J. M. ( 1983). Delusions and delusional thinking in psychotics: A review of the literature. Clinical Psychology Review, 3, 227-253.

Zimbardo, P. G., Andersen, S. M., \& Kabat, L. G. (1981). Induced hearing deficit generates experimental paranoia. Science, 212, 15291531 .

Received February 15, 1993

Revision received June 15, 1994

Accepted June 15, 1994

\section{Instructions to Authors}

Most of the articles published in the Journal of Abnor$m a l$ Psychology are reports of original research, but other types of articles are acceptable. Short Reports of replications or of failures to replicate previously reported results are given serious consideration. Comments on articles published in the journal are also considered. Case studies from either a clinical setting or a laboratory will be considered if they raise or illustrate important questions that go beyond the single case and have heuristic value. Manuscripts that present or discuss theoretical formulations of psychopathology, or that evaluate competing theoretical formulations on the basis of published data, may also be accepted. For further information on content, authors may refer to the editorial in the February 1991 issue of this journal (Vol. 100, No. 1, pp. 3-4).

Authors must prepare manuscripts according to the Publication Manual of the American Psychological Association (4th ed.). All manuscripts must include an abstract that contains a maximum of 960 characters and spaces (which is about 120 words) typed on a separate sheet of paper. All copy must be double-spaced, and further typing instructions, especially in regard to tables, figures, references, metrics, and abstracts, appear in the Manual. Also, all manuscripts are subject to editing for sexist language.

In preparing a Short Report, authors ought to set the character-space limit at 60 characters per line and ought not to exceed 410 lines of text and references (exclusive of the title page, abstract, author note, footnotes, tables, and figures). There should be no more than two figures or tables. As for regular manuscripts, the abstract must not exceed 960 characters and spaces.

Masked reviews are optional, and authors who wish masked reviews must specifically request them when they submit their manuscripts. For masked reviews, each copy of the manuscript must include a separate title page with the authors' names and affiliations, and these ought not to appear anywhere else in the manuscript. Footnotes that identify the authors must be typed on a separate page. Authors are to make every effort to see that the manuscript itself contains no clues to their identities.

Articles, except where other limits are specified, must not be longer than 36 manuscript pages, unless they report an unusually large series of studies or present unusually important detail. Case studies are ordinarily no longer than 16 manuscript pages. Comments ought not to exceed half the length of the original article. For Short
Reports, the length limits are exact and must be strictly followed.

APA policy prohibits an author from submitting the same manuscript for concurrent consideration by two or more publications. In addition, it is a violation of APA Ethical Principles to publish "as original data, data that have been previously published" (Standard 6.24). As this journal is a primary journal that publishes original material only, APA policy prohibits as well publication of any manuscript that has already been published in whole or substantial part elsewhere. Authors have an obligation to consult journal editors concerning prior publication of any data upon which their article depends. In addition, APA Ethical Principles specify that "after research results are published, psychologists do not withhold the data on which their conclusions are based from other competent professionals who seek to verify the substantive claims through reanalysis and who intend to use such data only for that purpose, provided that the confidentiality of the participants can be protected and unless legal rights concerning proprietary data preclude their release" (Standard 6.25). APA expects authors submitting to this journal to adhere to these standards. Specifically, authors of manuscripts submitted to APA journals are expected to have available their data throughout the editorial review process and for at least 5 years after the date of publication.

Authors will be required to state in writing that they have complied with APA ethical standards in the treatment of their sample, human or animal, or to describe the details of treatment. A copy of the APA Ethical Principles may be obtained by writing the APA Ethics Office, 750 First Street, NE, Washington, DC 20002-4242.

Authors submit five (5) copies of their manuscripts. All copies must be clear, readable, and printed on paper of good quality. A dot matrix or unusual typeface is acceptable only if it is clear and legible. Dittoed or mimeographed copies are not acceptable and will not be considered. It is suggested that authors keep a copy of the manuscript to guard against loss. Manuscripts are not returned except on request.

In addition to postal addresses and telephone numbers, authors are requested to supply electronic mail addresses and fax numbers, if available, for use by the editorial and production offices. Mail manuscripts to the Editor, Milton E. Strauss, Department of Psychology, Case Western Reserve University, 10900 Euclid Avenue, Cleveland, Ohio 44106-7123. 